\title{
EVALUVATION OF NOISE LEVEL AND ITS ADVERSE EFFECT IN METAL DIE MANUFACUTURING INDUSTRY
}

\author{
${ }^{1}$ N.Maheswaran, ${ }^{2}$ K. Visagavel \\ ${ }^{I}$ PG Scholar, Industrial Safety Engineering, Department of Mechanical Engineering, Knowledge Institute of \\ Technology, Salem, Tamilnadu \\ ${ }^{2}$ Professor, Department of Mechanical Engineering, Knowledge Institute of Technology, Salem, Tamilnadu
}

\begin{abstract}
Noise generated from industries is a prominent health problems and social problems and it causes of acute and chronic diseases such as cardiovascular dieses, acoustic trauma, noise induced hearing loss, hindrance communication between the employees, fatigue and loss of concentration. The noise induced hearing loss affects the both ears simultaneously. This paper is related to study about noise in metal die manufacturing industry by using sheet metal works in various operations. The power press is playing major role in sheet metal die manufacturing industry which is more noise generating machine. Several types of noises are observed from the various machines involved in sheet metal works exceeding the OSHA TWA (Time weighted average) standards. Noise induced hearing loss and environment pollutions are the main cause of such kind of industries. Goal of the study is to evaluate the noise level in those small scale industries and suggested to alleviate the noise level and its annoyances to development of safe and healthy work environment for the workers in press tool industries.
\end{abstract}

Keywords: Noise, Metal die manufacturing, power press

\section{INTRODUCTION}

Environment pollution is challenging factor for human nowadays, noise is an unwanted uninterrupted sound it is a big contributing cause of annihilate the calmness. Noise is an annoying one from many industries which involves as a cause occupational disease. The noise generated by numerous types of operations from the metal die manufacturing industry, includes many operations such as power press operations, surface grinding, drilling operation, bench grinding and hammering and generator operation. This is very imperative to evaluate the noise level in various operations and find the solutions to mitigate or eliminate the hazard from that industry.

Koffeman. A., et. al (2000) studied that twenty million employees are deployed in more than $85 \mathrm{~dB}$ working environment in United States of America. This is very common for the modern industries and it can be the great expenditure and creates permanent health effect, noise created acute and chronic health effects for human. Ivarson A., et al (1992) stated that nine percentages of industrial labors are exposed to excessive noise in Sweden. Alleyne., et al (1989) stated that compensation of hearing loss is very high which is estimated and revealed by Canadian compensation board, around C\$ 14000 used for compensation in average per year. Army Environment Hygiene Agency,1990 revealed that the united states has spend several amount for the reason of hearing loss and the adverse effect of noise pollution in occupational related dieses especially for permanent hearing losses and other relevant problems, the county has spend of \$200 million per calendar year 1990 .
Germano G., et al (1991) expressed that few noise analyzing experts were analyzed about the noise in certain industries and how it has created ill health affect like blood pressure increases and cardiovascular dieses for human. Chiplonkar SA et., al (2004) explained that the Hypertension is an important health issues which created by high noise, it causes for death heart attack, failure of lungs and stroke. Quis D et., (2001) stated that a pressing tool machine worker operates a high noisy machines more than eight hours per day. The operator had been disturbed physically and psychologically by the effect of incessant noise. It irritated the worker and his contribution. And also it creates behavioral change like nervousness for the operator. Igurnal $\mathrm{N}$ and Sozen et, al (2005) expressed that this kind of health problems can reduce the productivity, quality, safety, morality and good customer relationship.

While investigating a sheet metal die manufacturing industry, it is revealed that various kind of pollutions have been occurring such as air pollution, water pollution which may leads to hazardous environment. It is also found that more work related disabilities occurred during operation of the surface grinding and operation of power press which has 30 ton, 10 ton capacity respectively. It induces the author to measure the noise level at various location of the industry and discussed the solution for the reduction.

\section{METHODOLOGY}

Various types of sound level meters are available for measuring the sound such as sound survey meter, sound level meter, octave band analyzer, narrow band analyzer and noise dosimeter and impact sound level meter. In most of 
the industries used to measure the noise level by octave band analyzer and basic sound level meter.

The basic sound level meter is utilized to measure sound levels in various location (Fig.1) and its operations in metal die manufacturing industry. The sound levels were measured without running the machineries that are listed below.

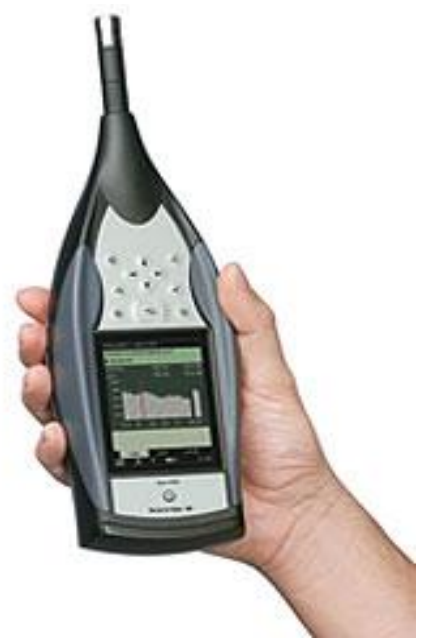

Fig.1 Noise Measuring Instrument
Table 1: Noise level measured during idle condition

\begin{tabular}{|l|l|l|l|}
\hline Sl.no & $\begin{array}{l}\text { Name of the } \\
\text { machine }\end{array}$ & Capacity & $\begin{array}{l}\text { Noise level } \\
(\mathbf{i d l e}) \mathbf{d B}_{\mathbf{A}}\end{array}$ \\
\hline 1 & Power press 1 & 30 Ton & 49 \\
\hline 2 & Power press 2 & 30 Ton & 50 \\
\hline 3 & Power press 3 & 10 Ton & 55 \\
\hline 4 & Surface grinding & 24 & 40 \\
\hline 5 & Drilling machine & $19 \mathrm{~mm}$ & 59 \\
\hline 6 & Bench grinder & $0.5 \mathrm{HP}$ & 59 \\
\hline 7 & Hand press & 5 Ton & 53 \\
\hline 8 & Generator & $250 \mathrm{KVA}$ & 52 \\
\hline 9 & Shaping & $2 \mathrm{HP}$ & 49 \\
\hline 10 & Milling machine & $5 \mathrm{HP}$ & 32 \\
\hline 11 & Torrent Lathe & $5 \mathrm{HP}$ & 45 \\
\hline 12 & $\begin{array}{l}\text { Wire cutting } \\
\text { machine }\end{array}$ & $15 \mathrm{HP}$ & 40 \\
\hline 13 & Shaping & $2 \mathrm{HP}$ & 55 \\
\hline
\end{tabular}

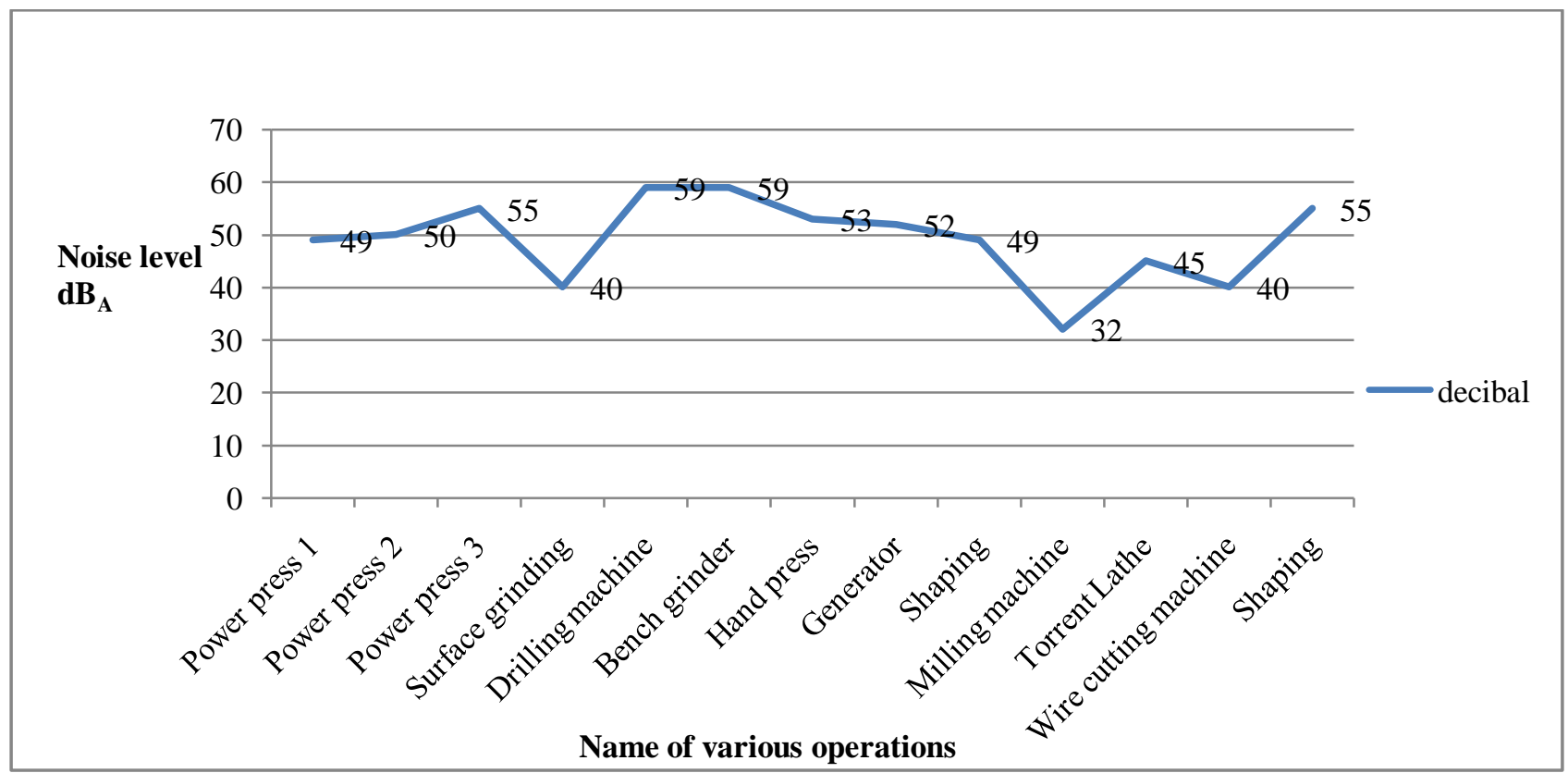

Fig 2: Noise level measured during idle condition

\subsection{Noise Level Measurements during Operation of}

\section{Machineries}

The similar kind of measurement was done in metal die manufacturing industry by using the basic sound level meter for observing the noise level. 30 ton power press emits more noise during the use of the heavy metal components. The generator also emits more noise during the operation in few hours. The turret lathe produces more noise while doing surface finishing and turning operations. According to the tool type and depth cut operations the lathe machine produce more noise. These measurements are tabulated in table 2 . Fig 2 is depicting the noise level measured during the operation. 
Table 2: Noise level measured during the operation

\begin{tabular}{|l|l|l|l|}
\hline Sl.no & $\begin{array}{l}\text { Name of the } \\
\text { machine }\end{array}$ & Capacity & $\begin{array}{l}\text { Noise level } \\
\text { (idle) } \mathbf{d B}_{\mathbf{A}}\end{array}$ \\
\hline 1 & Power press 1 & 30 Ton & 102 \\
\hline 2 & Power press 2 & 30 Ton & 99 \\
\hline 3 & Power press 3 & 10 Ton & 95 \\
\hline 4 & Surface grinding & 24 & 65 \\
\hline 5 & Drilling machine & $19 \mathrm{~mm}$ & 66 \\
\hline 6 & Bench grinder & $0.5 \mathrm{HP}$ & 68 \\
\hline 7 & Hand press & 5 Ton & 70 \\
\hline 8 & Generator & $250 \mathrm{KVA}$ & 98 \\
\hline 9 & Shaping & $2 \mathrm{HP}$ & 60 \\
\hline 10 & Milling machine & $5 \mathrm{HP}$ & 65 \\
\hline 11 & Torrent Lathe & $5 \mathrm{HP}$ & 90 \\
\hline 12 & $\begin{array}{l}\text { Wire cutting } \\
\text { machine }\end{array}$ & $15 \mathrm{HP}$ & 50 \\
\hline 13 & Shaping & $2 \mathrm{HP}$ & 50 \\
\hline
\end{tabular}

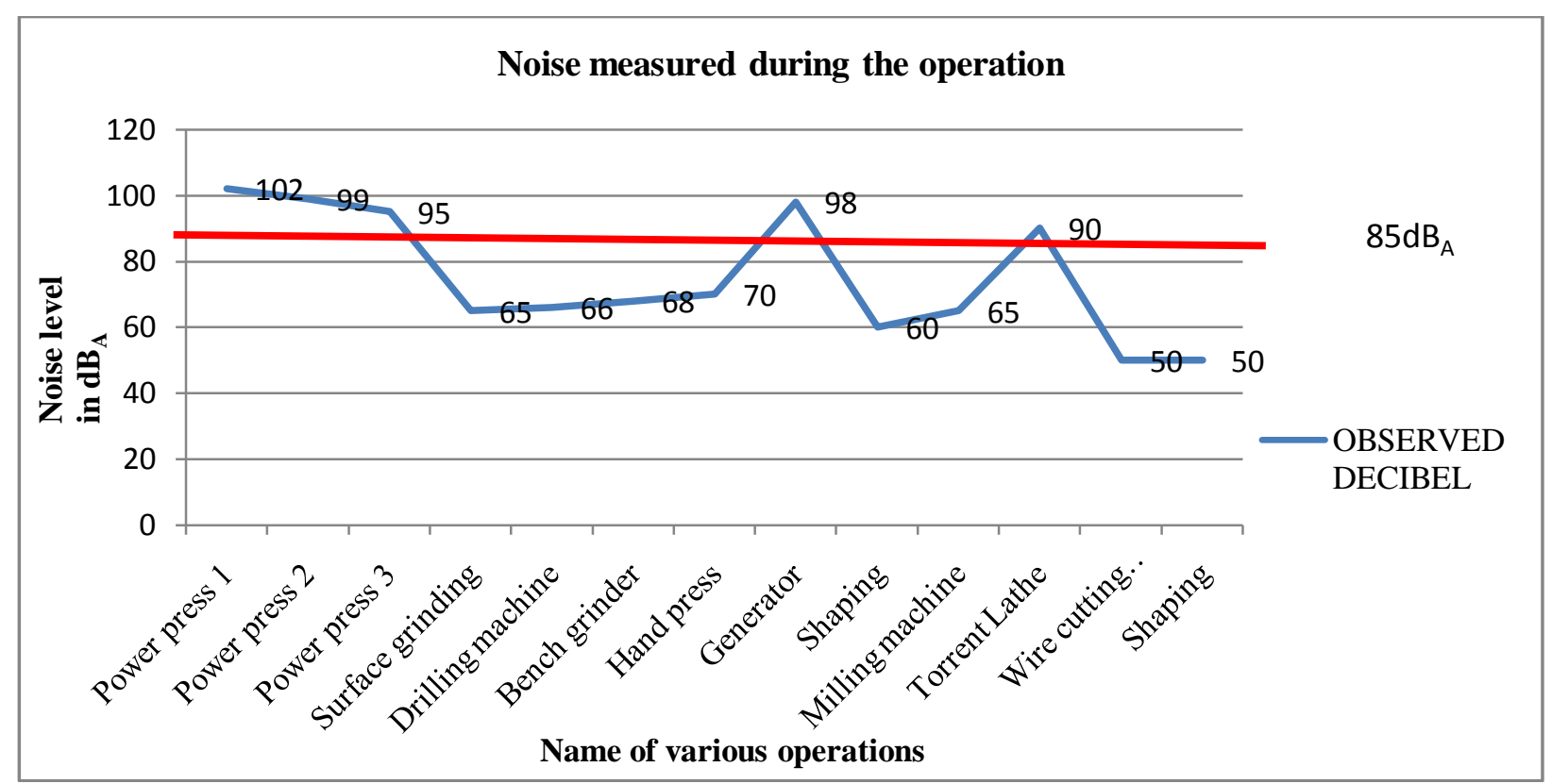

Fig: 3 Noise level measured during the operation

\section{RESULT}

Since operating all the machines in the above measured reading were measured during operation physically and evaluated. The graphical curves show that the sound level exceeds the recommended exposure limits. The sound levels in certain activities exceeds the OSHA table G-16 is in table 3

Table 3: OSHA standard sound level

\begin{tabular}{|l|l|}
\hline Duration per day & Sound level $\mathbf{d B}_{\mathbf{A}}$ \\
\hline 8 & 90 \\
\hline 6 & 92 \\
\hline 4 & 95 \\
\hline 3 & 97 \\
\hline 2 & 100 \\
\hline $1 \frac{1}{2}$ & 102 \\
\hline 1 & 105 \\
\hline $1 / 2$ & 110 \\
\hline $1 / 4$ or less & 115 \\
\hline
\end{tabular}

\section{CONCLUSIONS}

Result of the experimental work carried out in industry is compared with OSHA standards. It is clearly indicating that the metal work discharges more noise during operation of heavy metal component in the 30 ton power press machine. Author had observed also excessive noise discharged in the generator area. Finally, author is recommending that implementing proper acoustic proof for noise generating machines and using of ear muff by employees will reduce the ill effects. The industry which is implementing the above recommended engineering control measures will meet OSHA norms and also can achieve an safe working condition and environment for employees 


\section{REFERENCES}

[1]. Koffeman A, kerkers A. Cost optimal reduction of noise in large industrial areas- a method to select measures, noise - con 2000.Newport bench, California; December 0305,2000 .

[2]. Ivarson A, Bennrup S, Toremalm G. Models for studying the progression of hearing loss caused by noise. Scandinavian Audiology 1992; 21:79-86.

[3]. Alleyne BC, Dufresne RM, Kanji N, Reesal MR. Costs of workers ' compensation claims for hearing loss. Journal of Occupational Medicine 1989;31:134-8.

[4]. Army Environmental Hygiene Agency, Bio-Acoustics Division, Aberdeen, Md. Information determined from data obtained by the Agency from the Federal Office of Workers' Compensation Programs and the Veterans Administration, 1990.

[5]. Chiplonkar SA, Agte VV, TarwasiKV,Paknikar KM and Diwate UP. (2004). Macronutrient deficiencies as predisposing factors for hypertention in lacto-vegetarian Indian adults.J Am CollNutr: 23:239-247.

[6]. Quis D.(2001). Annoyance from road traffic noise: A review.J.Environ. Psychol.21:101-120

[7]. Igural N and Sozen M. (2005). Objective and subjective Examinations Related to the Noise Factor in Noisy plants and Analyses of the Noise Regulation. YTU, Faculty of Architecture.Electr.J.(1):9-17.

[8]. OSHA (Occupational safety and health administration) Standard no: 1910.95 